\title{
The position of the Sociedad Española de Patología Digestiva on the current situation of hepatitis $\mathrm{C}$ management in Spain
}

\author{
Sociedad Española de Patología Digestiva
}

\begin{abstract}
The advent of direct-action antivirals telaprevir and boceprevir has entailed a radical change in the healing possibilities for patients with hepatitis $\mathrm{C}$. This change has coincided with the emergence of highly robust evidence on the benefits of cure as regards increased overall survival, mainly brought about by a reduction in liver-related events in the long run. Therefore, a finite-in-time treatment is available that achieves very notable results both short- and longterm.

Triple therapy, consisting of the association of one of these novel drugs with the previously standard regimen of pegylated interferon and ribavirin, has come in the setting of a financial crisis, which has led to restrict its use primarily for patients with advanced fibrosis. These patients -who need a cure the most- are those with the lowest healing rates and the commonest, most severe side effects.

The time has then come to shift the aim point towards patients with less severe fibrosis, better cure rates, and fewer side effects where therapeutic intervention may prevent the development of significant liver disease.

Despite record-time approval by the European Medicines Agency, various barriers -mainly at the Autonomic regional levelhave delayed access to these therapies by our patients, thus giving rise to inequality situations.

New oral therapies are now on the near horizon that will increase the numbers of patients eligible for treatment with fewer side effects and a higher cure rate. We hope that the lesson is learned and no such situation will be repeated. An Integrated National Action Plan Against Hepatitis $\mathrm{C}$ would be an essential tool for countering this disease.
\end{abstract}

Key words: Hepatitis C. HCV management. Positioning.

Received: 03-12-2013

Accepted: 09-01-2014

Correspondence: Comisión de Excelencia Clínica. Sociedad Española de Patología Digestiva. c/ Francisco Silvela, 69, $2^{\circ}$ C. 28028 Madrid, Spain. e-mail: excelenciaclinica@sepd.es
Sociedad Española de Patología Digestiva. The position of the Sociedad Española de Patología Digestiva on the current situation of hepatitis $C$ management in Spain. Rev Esp Enferm Dig 2014; 106:46-50.

\author{
ABBREVIATIONS \\ HCV: Hepatitis C virus. \\ HIV: Human immunodeficiency virus. \\ IFN: Interferon. \\ PEG: Polyethylene glycol. \\ RBV: Ribavirin. \\ RNA: Ribonucleic acid. \\ SEPD: Sociedad Española de Patología Digestiva.
}

\section{INTRODUCTION}

Boceprevir and telaprevir are available in Spain for the treatment of hepatitis $\mathrm{C}$ since late 2011. The combination of these drugs -as triple therapy- with the conventional regimen of pegylated interferon and ribavirin (PEG-IFN$\mathrm{RBV}$ ) increases effectiveness in patients infected by genotype 1 by $30 \%$. This means a cure is achieved in over $70 \%$ of patients.

For years we have known that curing hepatitis $\mathrm{C}$ is possible, as opposed to other viral infections such as hepatitis B and HIV. Numerous pieces of evidence suggest that patients achieving sustained virological response, that is, undetectable HCV RNA at 3 months after treatment completion are in fact cured of hepatitis $\mathrm{C}$ virus infection.

There is in addition scientific evidence that curing this infection is associated with a number of histological benefits and, more importantly, a shift in the condition's natural history. It should be remembered that infection with hepatitis $\mathrm{C}$ virus is the primary cause of liver cirrhosis and 
liver cancer, and the first indication for liver transplant in western countries, specifically including Spain.

\section{HOW CAN WE INCREASE THE IMPACT OF HEPATITIS C CURE IN TERMS OF CIRRHOSIS AND LONG-TERM EVENTS?}

Various epidemiological studies find a prevalence of $2.5 \%$ for $\mathrm{HCV}$ infection among the general population, with variations according to age. A first incidence peak may be seen between 20 and 30 years of age in association with intravenous medications, and then an ascending curve from 50 to 70 years. Most cases of parenteral infection are likely the result of non-screened transfusions before the 1990 s, and of non-sterilized medical tool use. The number of acute hepatitis has decreased in recent years because of increased transfusion safety and a reduction in parenteral medication use, at least in our setting. However, numerous cases of acute hepatitis are still reported, some of them in epidemics, most commonly in association with nosocomial infection and also medical instrument use.

A recent study (the Discovery Study) (1) has described in detail the profile of patients in our country. This study, which included data from over 1,000 patients followed up in various hospitals, showed that mean age was between 41 and 60 years. Time from diagnosis was most commonly 11-20 years, and genotype 1 (76\%) -particularly $1 \mathrm{~b}$-was most frequent. Over half of patients had F3 or F4. Of these, $30 \%$ had never received treatment. The primary reasons for lack of treatment included waiting for new medications, patient refusal, and therapy contraindications.

Most recent evidence on the impact of new therapies derives from a study by Deuffic et al. (2), published in Gastroenterology, where a mathematical Markov model was used to predict the progression of HCV infection in several European countries, cirrhosis development, and HCV-related mortality in the next few decades.

Overall, therapy with PEG-IFN-RBV is seen to have reduced the incidence of liver cirrhosis by $7 \%$ and HCVrelated mortality by $3.4 \%$ during the past decade. The model foresees that triple therapy, with the addition of boceprevir or telaprevir, will achieve a reduction of cirrhosis by $17.7 \%$ and mortality by around $10 \%$ by 2021 .

However, these data depend on 2 factors: Screening of populations at risk and access to novel therapies. These two factors vary among European countries. Using indirect data, the probability of $\mathrm{HCV}$ screening is estimated to be $60 \%$ in France, $40 \%$ in Germany, and $33 \%$ in Spain. Our country is also a straggler regarding access to new therapies by diagnosed patients.

In addition, when the natural history of the disease is analyzed, the model predicts that cirrhosis and liver-cell carcinoma cases will be on the rise in Spain till 2030, in contrast to other countries such as Italy, where the majority of infections occurred a decade before and maximal cirrho- sis rates are therefore expected today. This fact reflects that any action taken to improve diagnosis rates and access to therapy in our country may have an extraordinary impact on stopping the disease's natural progression to cirrhosis or cancer.

Likely, the most relevant conclusion of this study is that, in order to decrease HCV-related morbidity and mortality, better therapies are just not enough -we should also improve patient identification with routine screening and increase access to therapy.

In this regard, the availability of an Integrated National Action Plan Against Hepatitis C, including education aimed at the general population, routine screening both overall and for at-risk groups, general practitioner training, and tools allowing rapid access to specialists in liver conditions as well as to novel therapies.

Currently in Spain, hepatitis C -including its relevance and contagion routes- remains a largely unknown condition among the general population. Awareness campaigns would indirectly increase detection rates.

We should also try to educate our primary care physicians and other specialists to increase referral of infected patients to hepatology clinics. A huge pocket of patients remains in the hands of other physicians on various grounds, mostly due to lack of perception regarding infection relevance and long-term consequences. Patients reporting that their doctor had said the condition was not "active" since transaminases were only slightly elevated are still a common occurrence as of today. We should bear in mind that HCV infection, also known as the silent pandemics, remains asymptomatic even in advanced stages.

Our government agencies should commit themselves to speed up and facilitate the availability of both present and future therapies so that patients, once evaluated by a specialist, may be treated in an effective, straightforward manner.

\section{SHOULD WE SHIFT TREATMENT RECOMMENDATIONS TOWARDS PATIENTS WITH LESS SEVERE FIBROSIS?}

Regulatory agencies and scientific societies have issued clinical guidelines regarding the use of novel medications for hepatitis $\mathrm{C}$ (boceprevir and telaprevir). Thus, the American Association for the Study of Liver Diseases recommends triple therapy in all patients infected with genotype 1 . In the UK, the National Institute for Health and Clinical Excellence (NICE), which promotes that therapeutic decision-making be based upon scientific evidence and cost-effectiveness, also recommends this regardless of fibrosis extent.

In Spain, following these protease inhibitors (boceprevir and telaprevir) approval, the Agencia Española del Medicamento (AEMPS) summoned an expert panel in order to design their own clinical guidelines, which have been 
supported by the Asociación Española para el Estudio del Higado. In their making our country's financial situation was taken into account, as was the upcoming scenario of newer medications with similar or improved efficacy but a better side-effect profile. Therefore, this was all about selecting patients who would benefit from triple therapy the most.

These AEMPS guidelines established that all patients with moderate fibrosis (equal to or higher than F2) are candidates to triple antiviral therapy. Later, most Pharmacy Directorates in Spain's Autonomous Regions further restricted this (exclusively based on financial criteria) to only prioritize patients with F3 and F4. In many Autonomous Regions only patients with advanced fibrosis may be treated this way and those with F2 are excluded. Patients with advanced fibrosis include those with greater cure needs but also moderate response rates and higher sideeffects rates.

Therefore, the expert panel summoned by AEMPS in 2013 to update recommendations regarding hepatitis C management has again insisted on the need to treat patients with moderate fibrosis (F2). Multiple studies show that patients with moderate fibrosis have higher response rates and a better safety profile as compared to those with advanced fibrosis.

\section{WHAT THEN TO DO WITH PATIENTS WITH ADVANCED FIBROSIS? TREAT OR WAIT?}

Importantly, it should be remembered that most patients included in the telaprevir and boceprevir phase-III trials had mild to moderate fibrosis, and only around $10 \%$ had cirrhosis. Therefore, most data on patients with advanced fibrosis derive from real-world studies.

In these patients with advanced fibrosis a detailed assessment of efficacy and safety aspects is even more relevant when making treatment-related decisions.

From treatment effectiveness perspective, real-world data are available from early-access studies of telaprevir and boceprevir, where the whole population researched had advanced fibrosis. Cure-related data reported at the American Association for the Study of Liver Diseases (AASLD) meeting reveal positive results when patients are appropriately selected.

Moreover, anemia rates among cirrhotic patients in protease inhibitor trials, including those of telaprevir, were significantly higher as compared to non-cirrhotic patients (44\% vs. $34 \%$ ) (3). Therefore, follow-up should be more stringent for these patients.

These data from telaprevir trials are confirmed by the results obtained in the CUPIC cohort, a cohort of patients with advanced fibrosis failing previous therapy who were treated with triple therapy within a French early access program (4). This cohort showed that protease inhibitors (boceprevir and telaprevir) combined with PEG-IFN-RBV were associated with high rates of serious adverse events (up to $54 \%$ ) and, consequently, considerable early discontinuation rates $(47 \%)$. The most common side effect was anemia, which was seen in up to one third of patients. Erythropoietin was used in $62 \%$ of patients, and $18 \%$ of these required blood transfusions. Infections developed in $9 \%$ of patients, $5 \%$ had a decompensation, and up to $2.4 \%$ died.

When serious adverse events (infection, death, decompensation) are carefully analyzed, these are seen to concentrate in a specific patient subpopulation with low albumin levels and a platelet count below $100,000 / \mathrm{mm}^{3}$.

This has prompted specific recommendations, even by AEMPS, to individually tailor treatment decisions for these subjects. These patients should be made aware of their specific risks, and treatment should be administered in centers with expertise in the management of complicated advanced cirrhosis, ideally with liver transplant or a readily available access there to.

\section{HOW CAN WE AVOID BARRIERS TO ACCESSING NEW THERAPIES AT THE HEALTH CARE LEVEL?}

Besides the aforementioned highly restrictive criteria, many autonomous regions further limit therapies with clerical and bureaucratic hindrances, which results in inequalities in access to treatment for specific patients.

Local approval has been delayed in some Autonomous Regions, as well as the hospital availability of these effective therapies against hepatitis C. The Asociación Española para el Estudio de las Enfermedades del Hígado has publicly denounced these restrictions and reminded that consensus clinical guidelines have been issued that must be complied with.

In an attempt to make the experience with boceprevir and telaprevir useful to avoid future problems in accessing new therapies, we believe that the assessment of a novel therapy should be implemented by one single commission wherein the Health Ministry, autonomous regions, experts appointed by scientific societies, and patient associations should have representation. Such commission should issue recommendations to be directly applied in Spain's national territory with no exceptions and with no subsequent assessment required at the regional or hospital level.

All these regulations should be specifically included in the National Plan against Hepatitis $\mathrm{C}$ we are presently reclaiming.

Professionals need to inform political leaders about hepatitis $\mathrm{C}$ and its management via our scientific societies. We need to convince both our politicians and the citizens that financing treatments against hepatitis $\mathrm{C}$ is no expense but an investment for the future, as it prevents cirrhosis and cancer from developing and reduces liver transplantation needs, these being situations and therapies with a significantly higher cost. 


\section{WHICH ARE THE MOST IMPORTANT BARRIERS AT PATIENT LEVEL?}

We need trained professionals and informed patients.

Managing new medications requires new skills. Continued training efforts are needed for professionals, ideally led by independent scientific societies. These treatments are more complex to use and any computer-based aids would be most welcome.

Patient associations take great pains to inform patients. This is a key role to prevent them from receiving biased or wrong information from unreliable sources accessible in broadcast media such as the Internet.

A National Plan against Hepatitis C would specifically include public education even at school, as well as the need for continued education for both primary and specialized care practitioners.

\section{MAY BOCEPREVIR AND TELAPREVIR BE CONSIDERED THERAPEUTIC EQUIVALENTS?}

Boceprevir and telaprevir are approved medications for identical indications but their dosage, dosing schedules, and safety profiles differ. Even whether their effectiveness is comparable is unknown since no direct comparison studies are available. Any equivalence should be grounded on purposely designed clinical trials -it should not be inferred from an analysis of different studies. The fact that two antiviral drugs are classified in the same group or share the same therapeutic actions does not warrant their consideration as equivalent drugs in terms of safety or drug-drug interactions, or their interchangeability.

Governmental agencies should negotiate to obtain the best prices for approved drugs, and also inform practitioners on the expenses implied by the various options. Professionals, as committed to system sustainability, should take costs into account in order to prescribe efficiently.

A highly relevant shift has taken place as regards cure possibilities with an impact on the natural history of hepatitis $\mathrm{C}$, thus preventing cirrhosis and liver cancer development. These advances result from selecting the best drug therapy strategy and tailoring treatment in accordance with patient characteristics on an individual basis. Any regulation concerning these alternatives should be based on professional consensus rather than imposition by health care authorities.

\section{ACKNOWLEDGMENTS}

The Sociedad Española de Patología Digestiva is particularly grateful to José Luis Calleja for the wording of this positioning, and to Fernando Carballo for his coordination as manager of his Clinical Excellence Commission. We are also grateful to Teresa Tejerina and Manuel Romero for their primary review of the positioning statement, and to the members of the society's board and committees for their review and subsequent approval. SEPD is finally grateful to Teresa Tejerina, José Ángel Sánchez, José Javier Herranz, and Antonio Fernández for their contributions as proponents during the institutional conference on the impact of hepatitis C on the National Health System, held at Digestive Diseases Week 2013. This conference was chaired by Fernando Carballo and included SEPD speaker José Luis Calleja, and served as a basis for the making of this positioning statement.

\section{CONFLICTS OF INTEREST}

This positioning has been drafted with no direct or indirect interventions or contributions from outside the Sociedad Española de Patología Digestiva.

\section{REFERENCES}

1. Buti M, Moreno E, Carmona I, Sánchez Ruano JJ, Sanso A, Berenguer M, et al. Estudio DisHcovery: perfil clínico, manejo y seguimiento de los pacientes con hepatitis crónica $\mathrm{C}$ en hospitales españoles: Asociación Española para el Estudio del Hígado 2013: póster 86.

2. Deuffic-Burban S, Deltenre P, Buti M, Stroffolini T, Parkes J, Mühlberger N, et al. Predicted effects of treatment for HCV infection vary among European countries. Gastroenterology 2012;143:974-85.

3. Pol S, Roberts SK, Andreone P, Younossi ZM, Diago M, Lawitz E, et al. Efficacy and safety of telaprevir-based regimens in cirrhotic patients with HCV genotype 1 and prior peginterferon/ribavirin treatment failure: Subanalysis of the REALIZE phase III study. Hepatology 2011;54:374A-5A.

4. Hezode C, Dorival C, Zoulim F, Poynard T, Mahurin P, Pol D, et al. Safety of telaprevir or boceprevir in combination with peginterferon alfa/ribavirin, in cirrhotic non responders. First results of the French early access program (ANRS CO20-CUPIC). J Hepatol 2013;58:S27. 